Relations industrielles

Industrial Relations

\title{
The Transition from School to Work, The Princeton Manpower Symposium, May 9-10 1968, Princeton University, New Jersey, 282 pages.
}

\section{L.-René Parenteau}

Volume 24, numéro 2, 1969

URI : https://id.erudit.org/iderudit/028036ar

DOI : https://doi.org/10.7202/028036ar

Aller au sommaire du numéro

Éditeur(s)

Département des relations industrielles de l'Université Laval

ISSN

0034-379X (imprimé)

1703-8138 (numérique)

Découvrir la revue

Citer ce compte rendu

Parenteau, L.-R. (1969). Compte rendu de [The Transition from School to Work, The Princeton Manpower Symposium, May 9-10 1968, Princeton University, New Jersey, 282 pages.] Relations industrielles / Industrial Relations, 24(2),

455-455. https://doi.org/10.7202/028036ar

Tous droits réservés @ Département des relations industrielles de l'Université Laval, 1969
Ce document est protégé par la loi sur le droit d'auteur. L’utilisation des services d'Érudit (y compris la reproduction) est assujettie à sa politique d'utilisation que vous pouvez consulter en ligne.

https://apropos.erudit.org/fr/usagers/politique-dutilisation/ 
autorités publiques pourra être nécessaire pour inciter les travailleurs à délaisser les industries et les régions en déclin pour d'autres plus favorables où il $\mathrm{y}$ a manque de main-d'oeuvre.

La présente étude, qui concerne les travailleurs urbains, fournit des informations sur le nombre et l'orientation de leurs déplacements vers de nouveaux emplois lorsqu'ils changent soit de profession, soit d'industrie, soit d'implantation géographique. Elle donne un aperç des forces qui entrent en jeu pour déterminer la direction et le choix des personnes qui acceptent ou refusent le déplacement. Elle pourra servir de base à un examen détaillé des grands problèmes que pose l'élaboration d'une politique active de la main-d'oeuvre et les conclusions qu'elle tire sont provisoires et approximatives. Enfin, cette étude énumère plusieurs éléments indispensables à la mise au point d'un système intégré.

La question fondamentale que pose cet ouvrage est de savoir si le cadre institutionnel existant aboutira à un mécanisme du marché et à une structure des salaires capables de provoquer une mobilité qui, en volume et en variété, correspondra exactement aux besoins de l'économie. Les obstacles principaux sont de caractère social et institutionnel; le manque de souplesse de la structure des salaires et l'existence de perspectives de revenus distincts des gains habituels. Les auteurs concluent néanmoins que la mobilité volontaire a plus de chance d'améliorer la répartition de la main-d'oeuvre que la mobilité involontaire.

\section{Pierre DIONNE}

The Transition from School to Work, The Princeton Manpower Symposium, May 9-10, 1968, Princeton University, New Jersey, 282 pages.

Ce volume présente dix études de base préparées pour un symposium à Princeton. Organisé conjointement par des organismes gouvernementaux et par des centres de recherches, le symposium avait pour but d'étudier le chômage chez les jeunes. En fait, il s'agissait bien plutôt d'étudier les difficultés rencontrées par les jeunes du niveau secondaire qui, n'allant pas au niveau collégial, entre après ce premier cycle d'étude sur le marché du travail. A partir de la définition du problème et de l'inventaire de ces difficultés, les participants au symposium approchent, tour à tour, les causes profondes de ce phénomène, les centres responsables et élaborent quelques solutions.

Une soixantaine d'experts se sont penchés sur le problème; ils venaient soit des milieux de l'éducation, des affaires et du gouvernement, soit des syndicats et associations. Leurs études, et spécialement celles rapportées dans ce volume, peuvent être regroupées sous trois titres principaux :

1. - les dimensions du problème du chômage chez les jeunes aux Etats-Unis;

2. - les expériences étrangères pour solutionner ce problème;

3. - les mécanismes pour aménager le passage des jeunes de l'école au travail.

Les experts n'ont pas manqué de signaler ici la responsabilité des écoles, des employeurs et du gouvernement pour prendre conscience du problème, pour chercher les solutions adéquates et les appliquer.

Il y a dans ces dix études plus que l'étude du problème, tel que ressenti aux Etats-Unis; il y a la définition de variables et facteurs clés pour approcher le problème, des méthodes de calcul pour évaluer son ampleur, des solutions propres à toute société industrielle qui fait face au chômage chez les jeunes. Nous aurions avantage à développer ces études dans le contexte québécois, à adopter les méthodes de calcul, à discuter les solutions d'un problème que nous allons rencontrer d'ici peu. En effet, au même titre que les sociétés industrielles occidentales, nous allons connaître très bientôt, à la suite de la démocratisation de l'enseignement, le problème d'intégrer au marché du travail un fort pourcentage d'étudiants qui ne sont pas aptes ou qui ne veulent pas continuer leurs études au niveau collégial ou universitaire. Il sera important, à ce moment-là, non seulement de connaître l'impact social de ce phénomène mais aussi d'avoir prévu longtemps à l'avance les mécanismes régularisateurs et le partage des responsabilités.

L. René PARENTEAU 